\title{
Bundesverfassungsgericht und überstaatliche Gerichtsbarkeit
}

\author{
Prozedurale und prozessuale Mechanismen zur Vermeidung und Lösung von
} Jurisdiktionskonflikten

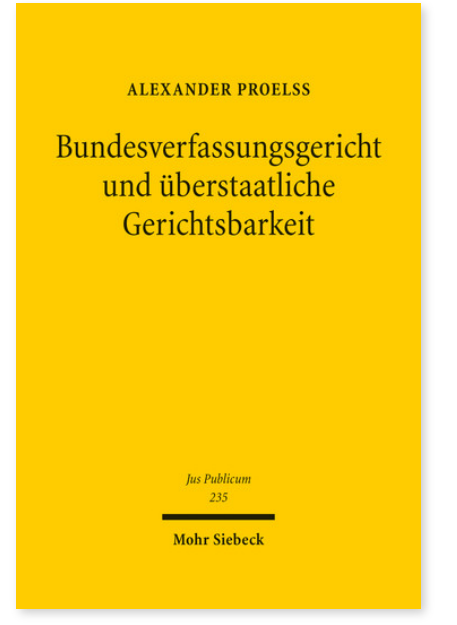

2014. XVII, 342 Seiten. JusPubl 235

ISBN 978-3-16-153280-1

DOI 10.1628/978-3-16-153280-1

eBook PDF $114,00 €$

ISBN 978-3-16-153279-5

Leinen $114,00 €$
Alexander Proelß widmet sich der Vermeidung und Lösung von Rechtsprechungskonflikten zwischen dem Bundesverfassungsgericht einerseits und der überstaatlichen Gerichtsbarkeit, insbesondere dem Gerichtshof der Europäischen Union, dem Europäischen Gerichtshof für Menschenrechte und dem Internationalen Gerichtshof andererseits. Diese Konflikte können sich aus der Überlagerung gerichtlicher Zuständigkeiten im Rahmen des bestehenden Mehr-EbenenSystems der friedlichen Streitbeilegung ergeben. Vom Standpunkt des positiven Rechts aus analysiert der Autor Anwendbarkeit, dogmatische Verortung, Reichweite und Konsequenzen von prozeduralen und prozessualen Mechanismen, die den verfassungsgerichtlichen Prüfungsmaßstab bzw. die entsprechende Kontrolldichte und damit letztlich die Kompetenzen des BVerfG determinieren.

Alexander Proelß Geboren 1973; Studium der Rechtswissenschaft an den Universitäten Bonn und Tübingen; wiss. Mitarbeiter und Assistent an der Juristischen Fakultät der Universität Tübingen; wiss. Mitarbeiter am Bundesverfassungsgericht; 2007-10 Professor für Öffentliches Recht mit dem Schwerpunkt Seerecht an der Christian-Albrechts-Universität zu Kiel; seit 2010 Professor für Öffentliches Recht, insbesondere Völkerrecht und Europarecht, an der Universität Trier und Direktor des Instituts für Umwelt- und Technikrecht (IUTR) der Universität Trier.

Jetzt bestellen:

https://mohrsiebeck.com/buch/bundesverfassungsgericht-und-ueberstaatliche-gerichtsbarkeit-9783161532801?no_cache=1 order@mohrsiebeck.com

Telefon: $+49(0) 7071-923-17$

Telefax: $+49(0) 7071-51104$ 